\title{
EAJ-1 Radio Barcelona e as \\ revistas Radiosola e Radio Barcelona nos anos de 1920 e 1930
}

\section{Antonio Adami}

\section{Resumo}

Nosso objetivo é analisar as revistas Radiosola e

Radio Barcelona na consolidação da EAJ-1 Radio

Barcelona, a primeira estação oficial da Espanha, em 1924. A reflexão teórica tem como base publicações nos campos midiático e história dos meios.

Trabalhamos com a observação, análise documental, material audiovisual, pesquisa em jornais e revistas espanholas e entrevistas com profissionais da Radio Barcelona e das revistas citadas. A história oral nos foi extremamente útil para 0 viés diacrônico da pesquisa, dada a fertilidade oral do meio rádio. Concluímos que as revistas são de vital importância constituindo-se em esteio da rádio até o final da Guerra Civil (1939), tempos de grande turbulência política, e também importantes para o sucesso do cinema na Espanha, com capas ilustradas pelas mais belas atrizes da época.

\section{Palavras-chave:}

História dos meios. Rádio e política. Radio Barcelona. Revista Radiosola. Revista Radio Barcelona.

Antonio Adami I antonioadami@uol.com.br Doutor em Semiótica e Linguística pela Universidade de São Paulo (USP). Professor Titular do Programa de Pós-Graduação em Comunicação da Universidade Paulista (UNIP).

\section{Introdução}

Esta pesquisa trata do papel do rádio em um período importante da histórica política espanhola. Nossa reflexão teórica para a pesquisa tem como base estudos no campo midiático, cultura, história dos meios e sobre 0 meio rádio especificamente. Para dar conta da pesquisa em Barcelona, além da teoria utilizada, trabalhamos com entrevistas a profissionais da Radio Barcelona, como fontes primárias e levantamos informações em artigos de jornais e revistas e em gravações de áudio disponíveis, dos anos de 1920 e 1930.

Realmente as revistas Radiosola e a Radio Barcelona são importantes vetores para a consolidação da EAJ-1 Radio Barcelona. Esta é exatamente a questão que trazemos para este artigo, para entendermos um pouco mais da história dos meios de comunicação da Espanha, particularmente o rádio, e também um pouco da história da mídia impressa naquele país. Nesse sentido, em um primeiro momento buscamos compreender qual é a relação que a Radiosola tem com a revista 
Radio Barcelona, e também quais são as relações que ambas têm com a EAJ-1 Radio Barcelona e a Associación Nacional de Radiofusión (ANR). Esta Associação, a mais importante entidade de empresários do setor de radiodifusão da Espanha dos anos de 1920, realiza reuniões de outubro de 1923 até a constituição formal em fevereiro de 1924. Quem incentiva e promove a Associação são os fundadores da revista Radiosola, a primeira revista sobre radiodifusão da Espanha, o engenheiro José Maria Guillén-Garcia Gómez, primeiro diretor da Radio Barcelona, e 0 jornalista Eduardo Solá Guardiola, que juntos formam uma "dupla dinâmica", interessada em desenvolver a radiodifusão, atentos ao que ocorre na Europa e demais países de outras regiões. Aprovado o estatuto da ANR, obtêm em seguida a licença oficial para o início das transmissões da EAJ-1.

Nossa questão essencial estava em buscar informações sobre a história das duas revistas e da rádio, e isso só poderia ser respondido, primeiro com uma pesquisa na região, e, estando lá, organizar exatamente os passos que seriam dados para o êxito da pesquisa, planejada anteriormente aqui em São Paulo. Conseguimos muito material tanto impresso como audiovisual nos anais das bibliotecas, em centros culturais e na Universitat Autònoma de Barcelona (UAB). Em ambos os lugares percebemos que os documentos impressos e de áudio são cuidadosamente preservados e bem guardados, com tecnologia de preservação, principalmente no Arxiu Històric de La Ciutat de Barcelona. Este local, assim como i mijans de Comunicació, do Departamento de Cultura da Biblioteca da Catalunya, órgãos da Generalitat de Catalunya, possuem arquivos com vasto material e em excelente estado de conservação. Só tivemos acesso a muitos documentos com a apresentação generosa do professor Armand Balsebre, supervisor da pesquisa na $\mathrm{UAB}$, inclusive as publicações da Diputació de Barcelona, bastante raras. Interessante que estes locais têm grande preocupação com 0 armazenamento de informações e já possuem uma equipe pensando os passos da tecnologia de leitura e um acervo de máquinas capazes de ler registros mais antigos. Preocupação hoje generalizada em diversos países. Segundo o prof. Funari [1999] "É possível que em pouco tempo os centros culturais e bibliotecas tenham um museu de máquinas de leitura, pois não conseguem transferir constantemente os dados de um meio eletrônico para um mais atual", tamanha é a velocidade da tecnologia de armazenamento e leitura de informações.

\section{A ditadura de Primo de Rivera no nascimento do rádio espanhol e da revista Radiosola}

Para entendermos melhor a história do rádio na Espanha, nos anos de 1920 até 0 final da Guerra (1939), podemos organizar o período em diferentes fases: 
$1^{\text {a) }}$ os anos de nascimento (1924);

$2^{\text {a) }} 0$ rádio na ditadura de Primo de Rivera (1923-1930);

$\left.3^{a}\right)$ o rádio durante a Segunda República (1931-1935);

4ª) o rádio na Guerra Civil Espanhola (1936-1939).

A primeira rádio a operar na Espanha, em setembro de 1923, foi a EAJ-6 Radio Ibérica, a partir de Madri. A Radio Barcelona foi a primeira a ter a licença oficial, com o prefixo indicativo de EAJ-1. Entretanto, a Radio Ibérica já existia como uma rádio privada, mas de caráter paraoficial, inclusive servindo às forças militares. Sobre 0 assunto escreve Balsebre (2001, p. 43-44):

[...] la emisora Radio Ibérica inicia sus emisiones en sus instalaciones del Paseo del Rey en Madrid, con el visto bueno y tolerancia de la nueva Administración surgida del golpe militar de Primo de Rivera, a pesar de que la 'Lei de Radio' de 27 de febrero de 1923, a falta de un reglamento regulador que nunca llegó a aprobarse, hubiera declarado ilegales a todas las emisoras de radioaficionados que hubieran funcionado experimentalmente hasta el momento. Los proprietarios de Radio Ibérica supieron hacer valer las simpatías políticas con el nuevo régimen y los acuerdos comerciales que desde 1917 tenía la Compañía Ibérica con el Ejército y la Marina, a quienes la Compañía vendía sus equipos transmisores, facilitó que Radio Ibérica se amparase en una denominación de emisora 'para-oficial' para considerarse exenta de autorización. El resto de grupos promotores de nuevas emisoras aguardaron a la aprobación del Reglamento de junio de 1924 para registrar la solicitud de una licencia para la explotación legal de una emisora de radio. ${ }^{1}$

\section{A Radio Ibérica apresentaria uma solicitação} para licença somente no final de outubro de 1924 e receberia 0 indicativo de EAJ-6, um dia antes de sua inauguração oficial em 5 de novembro de 1924. Como podemos perceber realmente a Radio Barcelona é a primeira oficial, por apenas dois meses, com relação à Radio Ibérica, que esteve no ar até 1927, quando foi comprada pela Unión Radio, grupo que dominaria do final dos anos de 1920 até 0 final da guerra civil, várias das mais importantes emissoras da Espanha, inclusive a própria Rádio Barcelona.

Quanto à revista, o primeiro número da

Radiosola começa a circular em setembro de 1923, momento político em que Primo de Rivera, imbuído de ideais militaristas, de cunho nacionalista e autoritário, encabeça também no mês de setembro, precisamente em 13 de Setembro de 1923, um golpe de Estado,

"[...] la emisora Radio Ibérica inicia sus emisiones en sus instalaciones del Paseo del Rey en Madrid, con el visto bueno y tolerancia de la nueva Administración surgida del golpe militar de Primo de Rivera, a pesar de que la "Lei de Radio" de 27 de febrero de 1923, a falta de un reglamento regulador que nunca llegó a aprobarse, hubiera declarado ilegales a todas las emisoras de radioaficionados que hubieran funcionado experimentalmente hasta el momento. Los proprietarios de Radio Ibérica supieron hacer valer las simpatías políticas con el nuevo régimen y los acuerdos comerciales que desde 1917 tenía la Compañía Ibérica con el Ejército y la Marina, a quienes la Compañía vendía sus equipos transmisores, facilitó que Radio lbérica se amparase en una denominación de emisora "para-oficial" para considerarse exenta de autorización. El resto de grupos promotores de nuevas emisoras aguardaron a la aprobación del Reglamento de junio de 1924 para registrar la solicitud de una licencia para la explotación legal de una emisora de radio." 
suspendendo a Constituição, dissolvendo o

Parlamento e implantando uma ditadura militar.

0 golpe obtem apoio do rei Afonso XIII e de parte

do empresariado, do clero e das forças armadas.

Primo de Rivera cria um Directório Militar

que concentra todos os poderes do Estado,

acabando com a vida parlamentar. Ora, a revista

nasce nessse clima, de controle da sociedade

pelo Estado e total poder concentrado nas mãos

dos militares, nas elites e no clero conservador, que patrocinam o golpe. Vamos então discorrer brevemente sobre alguns fatos que marcam este período: 0 início da "barbárie" espanhola dos anos de 1920 e 1930.

Para entendermos melhor o momento a que nos referimos e o clima que impera naqueles anos, é necessário voltarmos um pouco para 1919, quando da chegada do General Primo de Rivera para trabalhar na península, pois seu serviço esteve marcadamente nas colônias da África. Neste momento Rivera começa a tomar conhecimento e a entender muito claramente o que se passa na Espanha de 1919. Entende também o vácuo deixado na esteira política $\mathrm{e}$ 0 abandono dos menos favorecidos da classe operária. Os problemas sociais e políticos da época são imensos, Segundo Bustillo (1978)
"[...] desde a gripe espanhola (1918-1919) as lideranças católicas controlando os sindicatos agrários, além do sentimento e de ações marcadamente de independência de algumas províncias, principalmente e notadamente a Catalunya [...]". Rivera, a partir daí, começa a planejar qual seria o momento ideal para um possível golpe de Estado.

Naquele momento, Primo de Rivera exerce o posto de capitão-general em Valência e Madrid, e em 1922 exerce o cargo na capital da Catalunya, em Barcelona. É ali que nota 0 maior e mais organizado movimento espanhol para a independência. Também observa graves problemas de ordem pública que na época afligem toda a região: terrorismo anarquista e pistoleirismo patronal, em pleno auge da militância catalã para a autonomia.

Com tanto assunto é até natural que além dos jornais diários haja também uma revista que represente os sentimentos da sociedade catalã. Junta-se a isso o nascimento do rádio e 0 deslumbramento crescente com 0 cinema. É 0 clima ideal para o lançamento da revista, não havia dúvida. Nesse clima nasce no ano 1 , número 1, a Radiosola. 

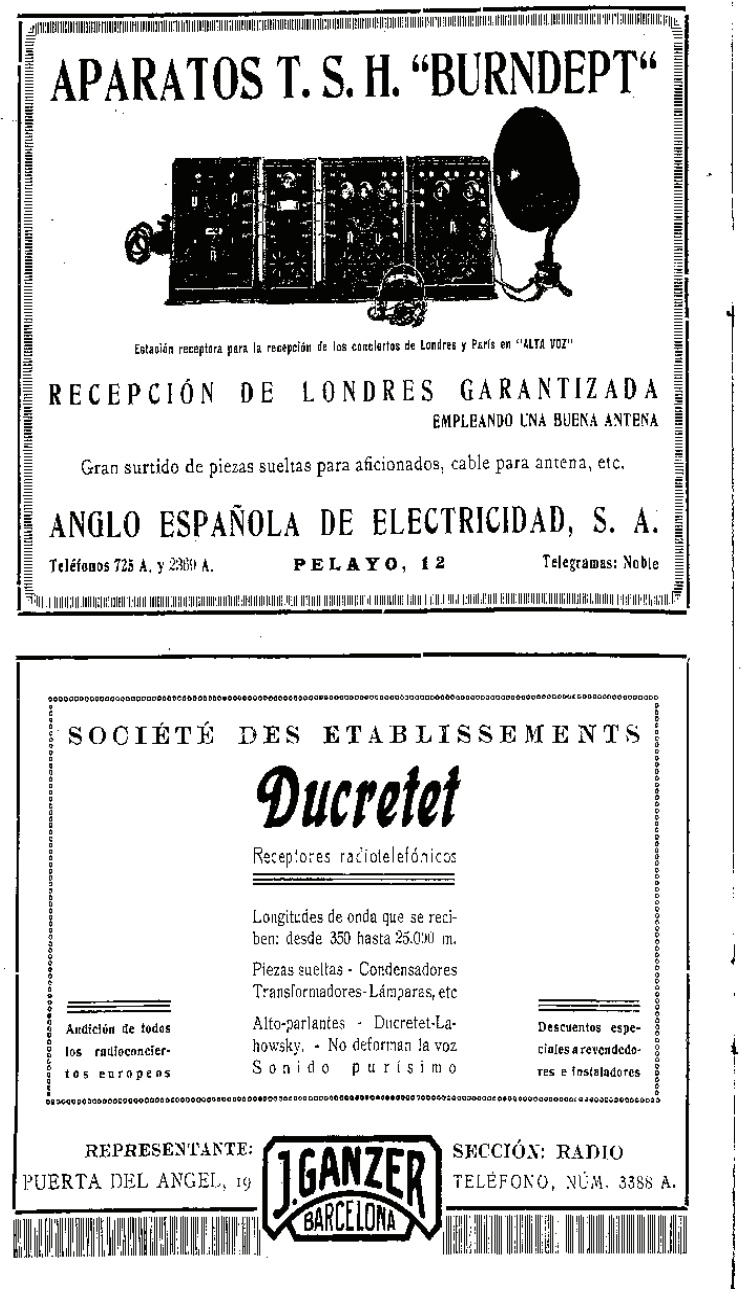
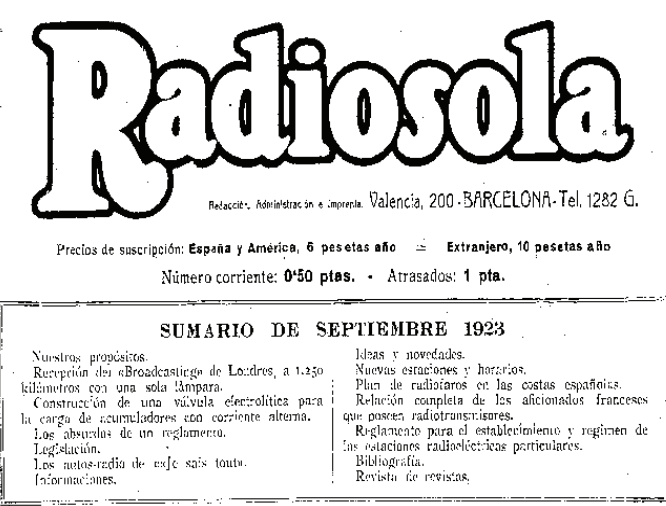

\section{Tuestros proposititos}

Es protzcolario que al aparecer una tueva publicación, sea ésta revista o diario, ten que hacerse la obligáda presentación, a la que siğue la exposición del programa ima ga que hacerse la obligada presentacion, a la que sigue la exposicion del programa ina puesto por sus organizadores. Amigos de la concisión, que es norma en nuestros aetos, sompentios el protocolo, $y$ lisa y llanamsente vamos en breves palabras a exponer nuestro pensamiento.

No sin razón decía, hace más đe veinte años, el célehre físico inglés Fíeming, a raiz de las experiencias de T. S. H. realizadas por Marconi al través del Canal de la Man: cha, que los más familiarizados en la radioelectricitad se sentian cada vez nuevamente impresionadios ante el hecho de que ef «Morsey marcara los puntos $y$ rayas que trans mitian las invisibles ondas eléctricas, impresiones que, dia tras otro, acumuladas en nues= mitian las invisibles ondas electricas, impresiones que, dia tras otro, acumuladas en nues-
tra imaginación se traducen ent tna seducción que sentimos todos los que dirigimos nues $=$ tros esfuerzos, a resolver los probiemas de radiocomanicación.

Natural es que, transcurriendo los años y perfeccionánóose sin cesar esta maravillo sa rama de la eltetrotécnia, han ido crecientứo los prosélitos de esta nueva ciencia de una mantera inesperada, y hoy pueden contarse por millones las personas que se interesan por la radiocomunicación, motivado en buena parte por el enorme desarrello que últimamente fia tomado la radiotelefonía, la que ha dado lugar a la creación de la bbra de cultura más hra tomado ia radiotelefonia, la que se ha conscido: La uradiodifusión o broadcastingy, que pone al aicance de to das las fortunas y en todos los lugares el medio de conocer el estado del tiempo, las coti= zaciones de los mercados, Las roticias más søbresalientes, las óperas más agraciadas, etc.

Este anhelo que existe por doquier, el iniciarse unos en los secretos de ia radio, el perfeccionarse en ella loss iniciados, y la necesidad que sienten los operadores terrestres y

Brithorolo

Fonte: Arxiu Històric de La Ciutat de Barcelona. 


\section{Figura 2 - Reprodução das páginas 2 e 3 da revista Radiosola (Espanha),} n. 1, de setembro de 1923 (continuação dos propósitos da revista).

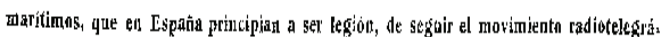
fico, nos ha decidido a lanzarnos a una emptesa que es syperior a nuestras iuerzas, que lio es otra gue lienar un vacio sentlido desde hace tiempo en las prises ibero-americanos, la de una revista radivejéctrica de disulgación, emprexa gue nu hubiéramas realizado si al-

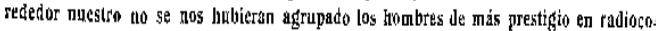

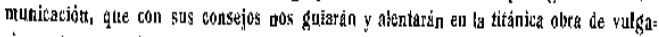
rizar esta nueva cientrin

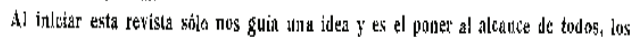
grandes deseubrimientos de la radiocowtinicación, en una palabra, la yulgarización de los fenómenos, en forma clura y amena, apartándose de teorias más o menas clegantes,

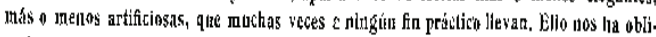

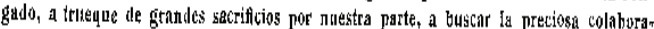

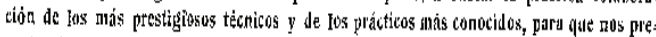
senten las coestiones en jorma concisa, libres de comentarios y consideraciones de alta cietciz, que sỏjo al sabio interesann, valiéndose, pera facilitar la penetración de sus idcas, del meyor nitincro posible de grabados y esquemas.

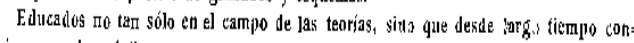
vivimos uns la práctica, reaus cuanta importancia tienc la experimentación, que es Ia hase para el conatimiento de ia uayoria de lon fenómenos y sobra ella levantar misis tarde la

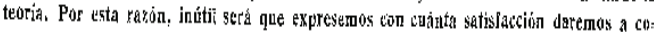
nocer todos los trabajos de expcrimentaciónt que se nos leemitan, venugan del lab'josatorio del sabio o del aficionado.

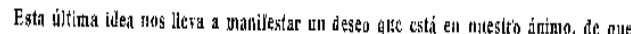

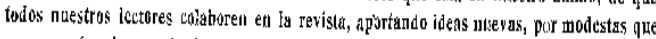
sean, y así podrennos diar logro a nuesiros deseos, que no son otros ifue liacer una resisto que sea vcruaderartente reffejo del sentir de nutestros leciores.

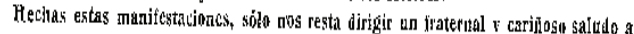
la prensa, especiajmente a la profesiontal, can el teses de mântener Ios más estrechos la:

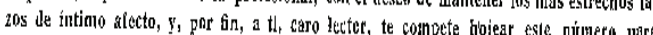

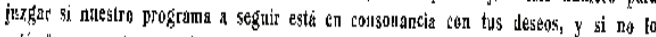
está, Irancamente toma la plitura y nos dices lo gute a tu juicio uebe lraccrse. la reu= nión de opirg̈nnes será nuestra nofma.

Num . subbles de su publicación, no intervienc directa ni indirectamente en ningull negocio de venta y explotacion de aparatas ni estacio. nes de T. S. H.

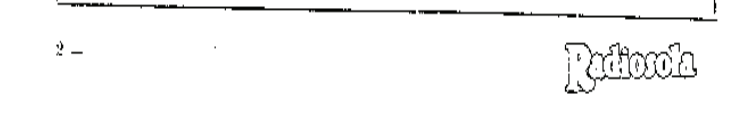

\section{Recepcion del "Groadcassiting" de Gondres a 1250 kilomettos con una sola lampara}

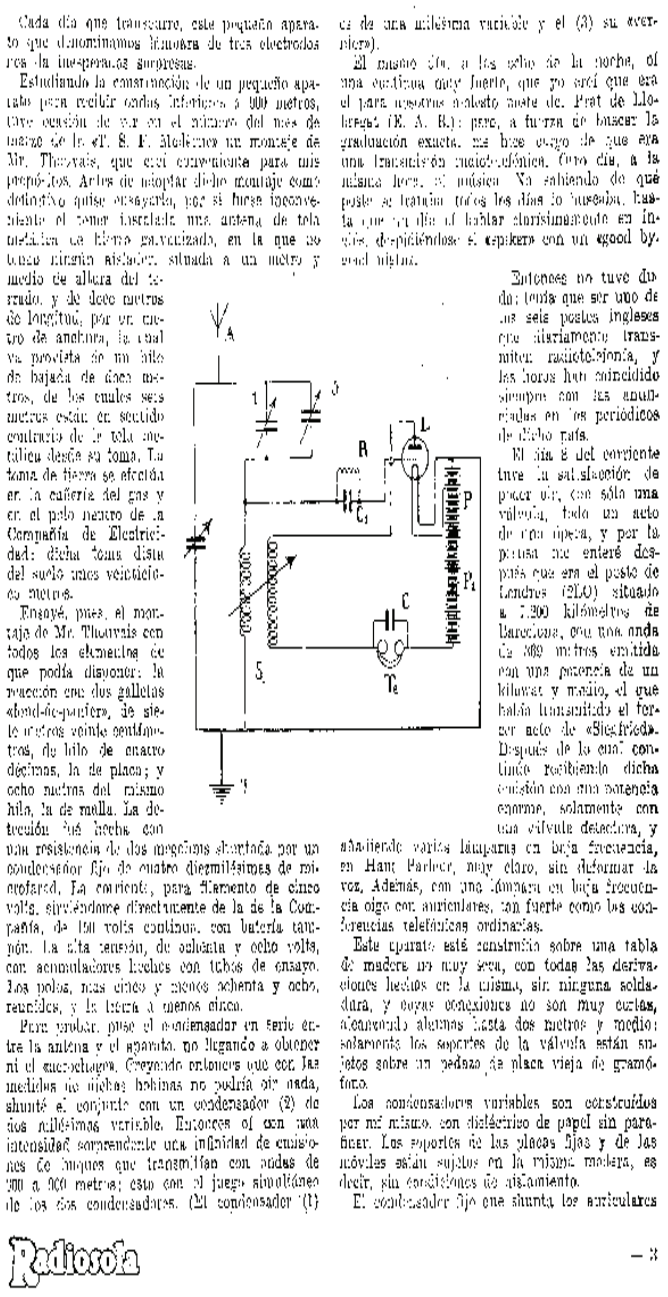

क

Fonte: Arxiu Històric de La Ciutat de Barcelona. 
0 editorial deixa claro que a revista, instalada a

"redacción, administración e imprensa", na Calle Valencia, nº 200 - Barcelona, seguirá uma linha científica e cultural. Privilegiará os acontecimentos e descobertas científicas relacionados à radiocomunicação e irá noticiar informações de especialistas e aficcionados no assunto. Portanto, é previsível que os editores da revista tivessem, naquele momento, a intenção de fomentar e introduzir o rádio em Barcelona e na Espanha, via revista Radiosola.

Guillén-García, fundador da ANR, exerce a função de diretor da revista e é posteriormente (1924-1926) também fundador e primeiro diretor da EAJ-1 Radio Barcelona. Mais do que fundador das revistas e da EAJ-1, GuillénGarcía tem monumental importância para a radiodifusão na Espanha. Filho de engenheiros, é ele quem traz os primeiros aparelhos para que, a partir do Hotel Colón, se faça a primeira transmissão radiofônica da Espanha. Solá, por outro lado, é fundador e gerente comercial da revista Radiosola, posteriormente um dos precursores do cinema em Barcelona. Sempre aficionado pelo cinema, tornou-se jornalista aos 22 anos no diário El Liberal e em 10 de junho de 1912 funda a primeira revista mensal de cinematografia, intitulada $\boldsymbol{E l}$ Mundo Cinematográfico, que em 1917 torna-se semanal. Juntamente com Guillén-García, é um pioneiro do rádio e participa de outros tantos projetos, praticamente desaparecendo da EAJ-1 a partir de 1925, para dedicar-se à produção e divulgação do cinema. Fica claro quando analisamos as capas da revista Radiosola e revista Radio Barcelona, a forte influência de Guardiola, com as mais importantes e belas atrizes de cinema da época, em destaque nas capas. Seus fundadores viveram, através das revistas e da EAJ-1, a história política e 0 nascimento da comunicação radiofônica de Barcelona e da Espanha, a partir de 1923.

A Radiosola, é publicada com este nome desde a sua fundação, como já escrevemos acima, em setembro de 1923, até a sua última publicação em julho-agosto de 1924, e continua a partir de 1924, com o nome de revista Radio Barcelona. Em seu primeiro número, seus fundadores escrevem um editorial reconhecendo o papel precursor da revista e enaltecendo sua função como importante meio de comunicação e divulgação. Ressaltam a criação da ANR, que é o núcleo para a criação da primeira estação oficial de rádio, instalada no Gran Hotel Colón, em Barcelona. 
Figura 3 - Reprodução da capa e última página, ano $1, n^{0} 1$, da revista RadioSola (Espanha), setembro de 1923
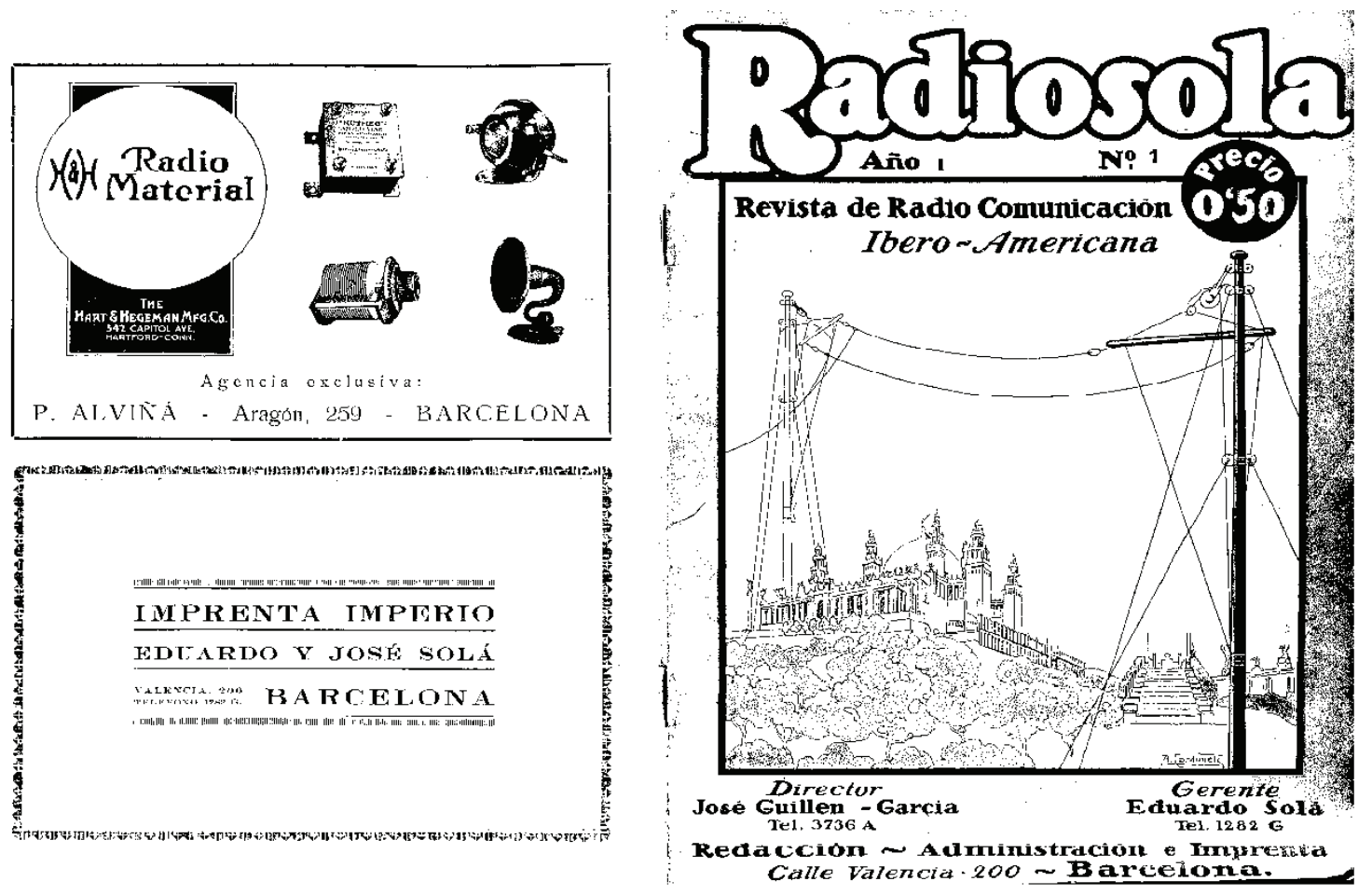

Fonte: Arxiu Històric de La Ciutat de Barcelona.

A revista Radiosola em seu primeiro número traz na capa locais de Barcelona; na página 1, 0 sumário e o editorial apresentam os propósitos da revista; nas páginas 3 a 8 , traz as mais recentes notícias sobre a radiodifusão: novas invenções, novas experiências em todo o mundo (lembrando que o meio rádio era a "coqueluche" do momento e de interesse geral); na página 9, observamos publicidade de produtos radioelétricos, que, assim como no Brasil, basicamente mantinham as estações no ar, pois os associados ainda eram poucos; nas páginas seguintes fotos de eventos relacionados com a radiodifusão e também mais publicidade, no geral vinculadas a produtos elétricos e telefônicos; também traz nas páginas seguintes as novas estações que surgem e os horários da programação. Interessante que naquele período cada emissora tinha certos horários definidos pela legislação, três ou quatro horas em alguns dias, não todos, até porque não conseguiriam operar 24 horas, pois não tinham capacidade técnica e nem conteúdo para tanto; também aparecem na revista os nomes e endereços de aficcionados de outros países que possuíam radiotransmissores; legislação para abertura de novas emissoras e listagem europeia de revistas que tratavam da radiodifusão.

Guillén-García e Solá publicam a revista Radiosola e assinam o editorial do último número, 11-12, de julho-agosto de 1924, convidando os leitores, profissionais e anunciantes, para uma nova fase. 
Figura 4 - Reprodução das páginas 12 e 13, da Revista Radiosola (Espanha), n. 1, de setembro de 1923 (novas estações e horários das transmissões radiotelefônicas de diferentes países: França, Tcheco-Eslováquia, Alemanha, Hungria, Itália etc.).

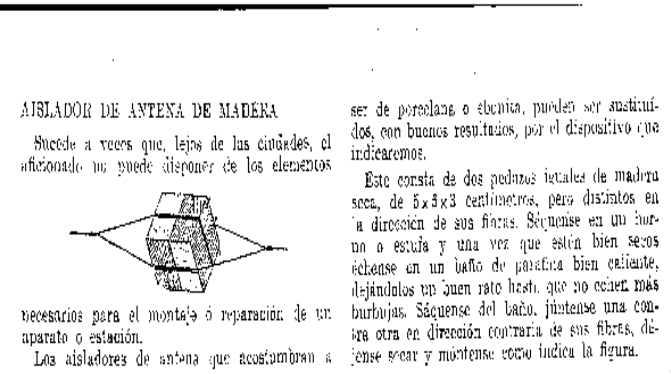

\section{Tuevas estaciones y horatios}

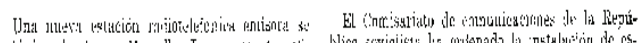

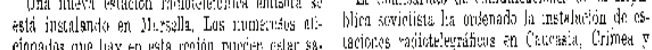

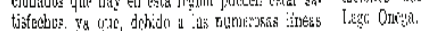

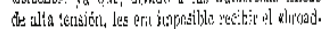
castir.ny de Radiolal

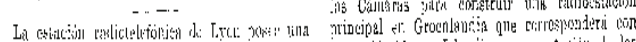

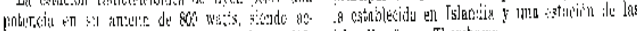

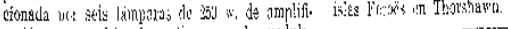

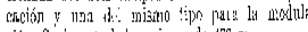

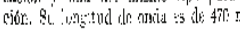

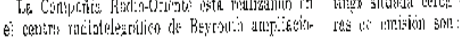

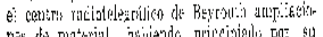

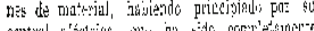

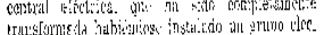

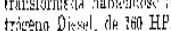

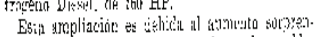

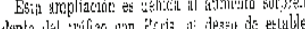

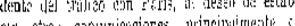

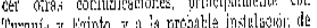

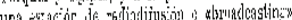

C-

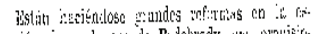

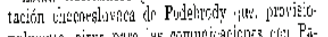

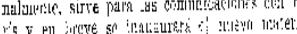

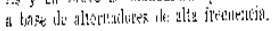

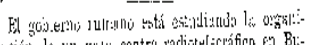

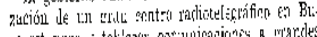

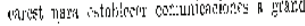

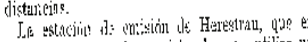

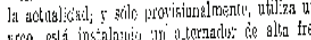

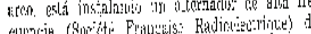
5!! Kx:

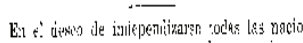

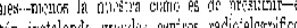
(an jesto Tecienter

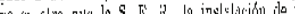
cron cen:ro ridio er: Bellgrado

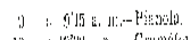

ii) i.

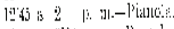

3 is

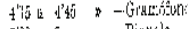

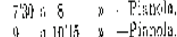

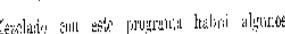

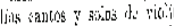

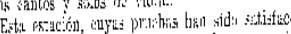

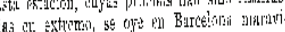

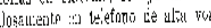

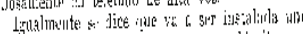

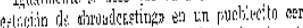

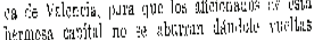
al axder 4 ilot.

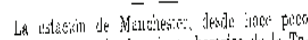

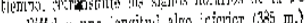

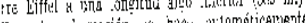

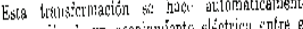

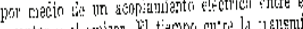

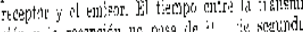

\section{Ten presente, aficionado, que la radioco.} municación es una apleación. de la electriv. cidad, Por que pretenndes estudiar una si poseer los conocimientos indigpensables de poseer los
la otra?

Profitoris

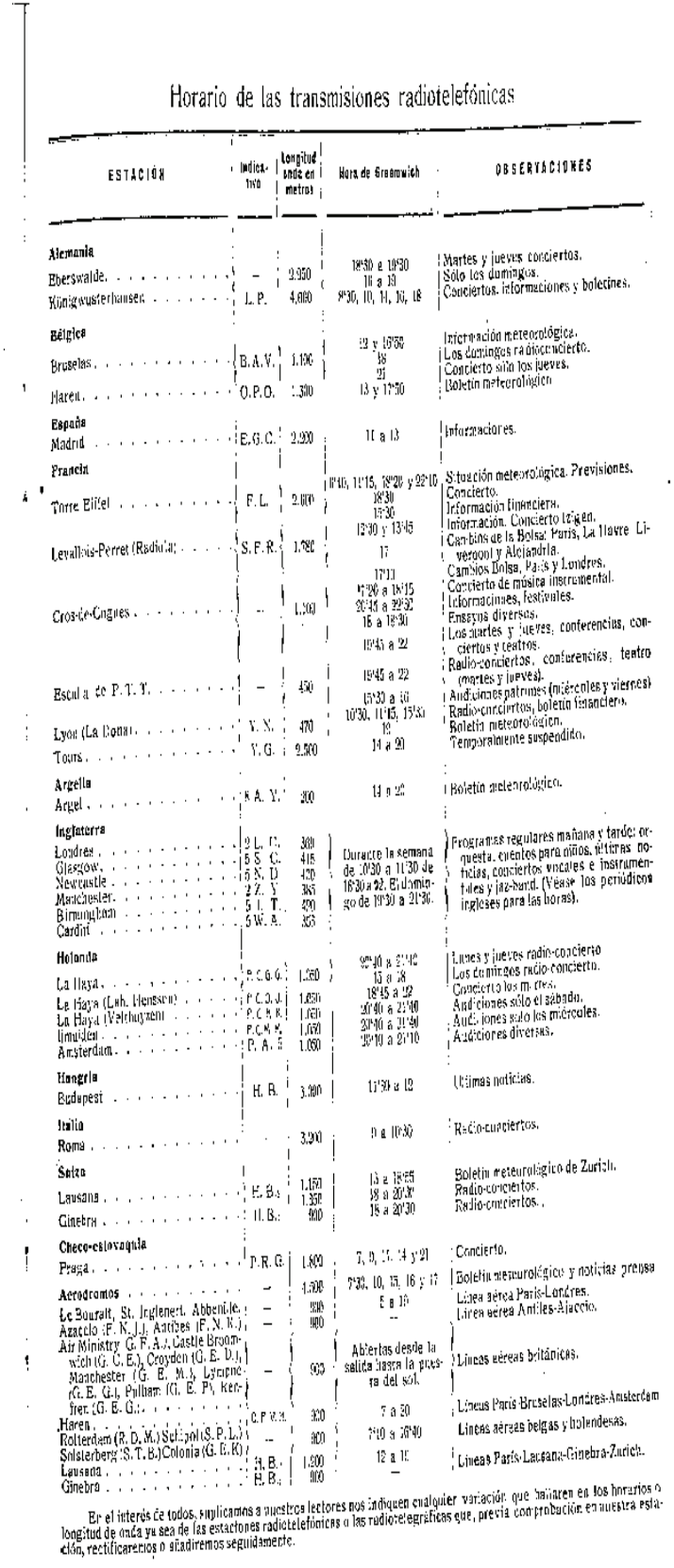

.

'承

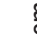

要 


\section{Revista Radio Barcelona}

Enquanto tudo isso acontecia, também apareciam várias rádios e a EAJ-1, pioneira, se firma como a mais importante emissora da Espanha. Todas as rádios têm um papel importantíssimo e estratégico para a guerra, mas vejamos este processo com a chegada da EAJ-1 Radio Barcelona (1924), no início das comunicações de massa na Espanha.

Com a chegada da rádio, a revista Radio

Barcelona passa a ser uma instituição independente para publicidade, programação e projetos, disvinculada da ANR. A revista segundo o editorial no primeiro número, continua com os princípios da Radiosola, mas com mais obrigações, inclusive noticiando a programação das principais rádios da Espanha e fazendo maior cobertura em cultura, política, ciência etc. Tudo o que ocorre na EAJ-1 a revista noticia e vice-versa. Ambas se ajudam comercialmente, cobrindo com maior facilidade e agilidade as pautas traçadas, naqueles difíceis tempos de grande tumulto político e social.

Figura 5 - Reprodução da capa e quarta capa da revista Radiosola (Espanha), n. 11-12, de julho-agosto de 1924 (último número da revista Radiosola)

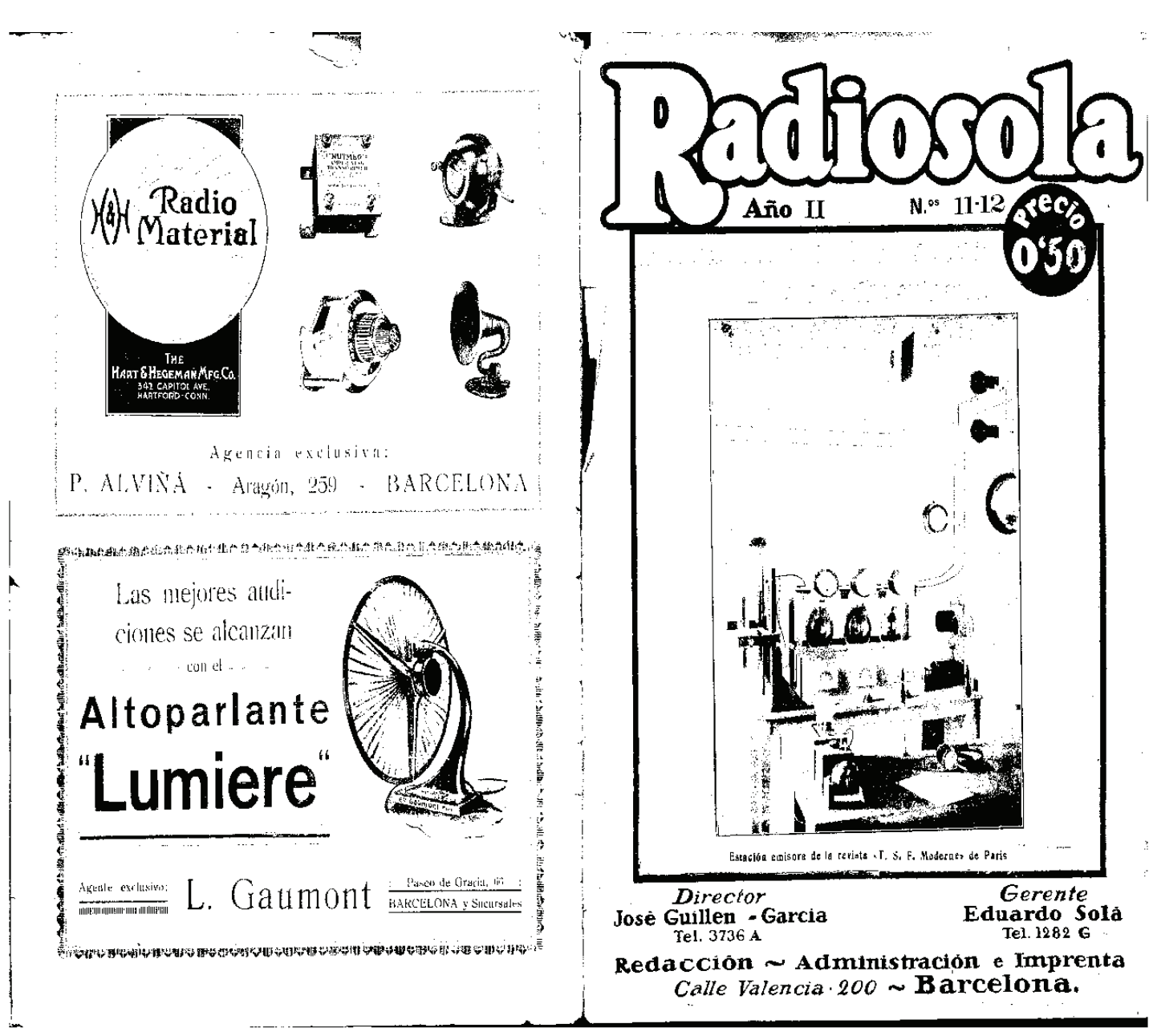

Fonte: Arxiu Històric de La Ciutat de Barcelona. Foto de capa: Estación emisora de la revista T.S.H. "Moderne" de Paris. 
Figura 6 - Reprodução da contracapa e página 1, da revista Radiosola (Espanha), n. 11-12, de julho e agosto de 1924 (balanço do último número da revista e lançamento da revista Radio Barcelona).

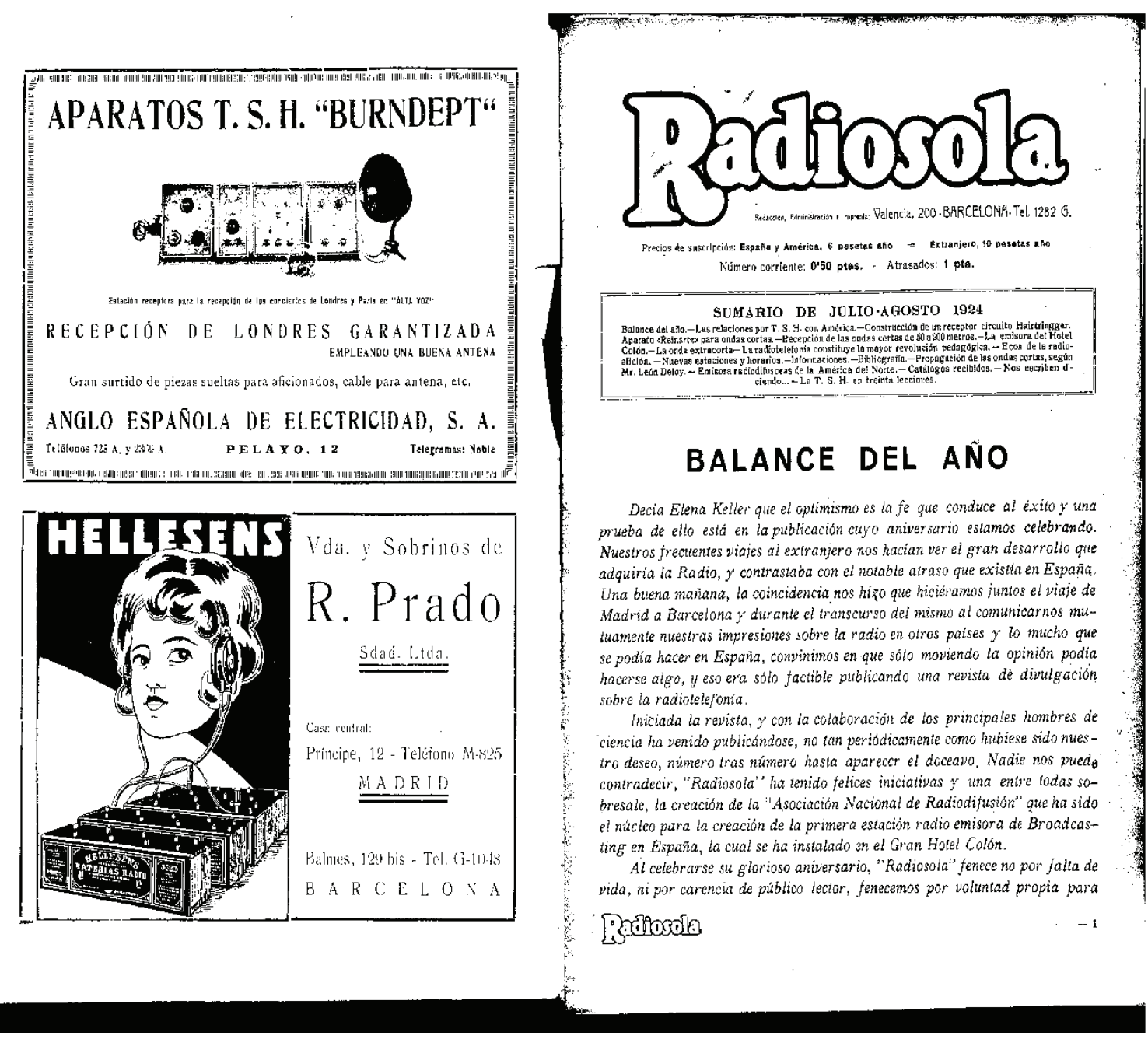

Fonte: Arxiu Històric de La Ciutat de Barcelona. 
Figura 7 - Reprodução das páginas 2 e 3, da revista Radiosola (Espanha), n. 11-12, de julho e agosto de 1924 (último número da revista e lançamento da revista Radio Barcelona).

evolucionar, para hacer algo más grande de lo que veria realizando. Hacemos como la larua que voluntarianente se transformase ent pupa pora luege. tomarse en policrona mariposa que alza el yneto para ir a regiones más elevadas que las de su antecesor.

"Radiosola" al crearse to "Asaciacion Nacional de Radididifusion" que al fon y a la pcsire es hija suta, hizo cuanto pudo desde suts columnas para que fueran un hectio tos propósitos que persegutia. Ha llegado el momento en que Radio Barcelona alcan; a la mayor edad y necesita un cirgano propio de proptganda destigada en absotuto de unos y" de otros. "Radiosola" siempre dispuesta a sacrificarse en benelicio de la Radio. cesa hoj su publicacion vara dejar el paso libre a la "Asuciación Nacional de Radiodifusion"

El optmismo de los que redactabamos esta revista, creyendo que este era el unico medio factible para desarollar la Radio en España, ha dado sus resutitados, es un thecho la radiodifusion en Barcelona. Con este solo hecho vemos satisfechos tantos anhelos que pusimos en favor de esta gran causa: la radiodifusion, gue a no dudar cantbin'á et modo de ser de los pueblos, como la cambió el maravilloso descubrimiento de Guttemberg gue higo dar un paso grgantesco en la cullura de tas pueblos.

Jose M." Guillen Ciarcia Eduardo Solá Guturdiola

Habiendo transferido desde cata feclas nuestra revista «Railinsofan a la entidad «Asociación Nacional de Radiodifusión», la que cortinuará ent adelante pablicándose se` maraimente con los programas detallados no sólo de la entsora de Barcelona, simo de las estaciones audibles en Espania y bajo el titulo de «Radio-Barcelona».

Suplicamos a nuestros aumerosos suscriptores y anunciantes se sirvan dispensar mejor acogida si cale que la dispensada a «Radiosola mos bastante.

NUEVA DIRECCIÓN:

\section{RADIOMBARCELONA}

\section{Caspe, 12, 1. D - Teléf, 4427 A. - BARCELONA}

$2-$

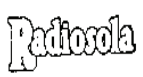

\section{LAS RELACIONES POR T. \&. H. CON AMEERICA}

$$
\text { pot Goguluin arraras }
$$

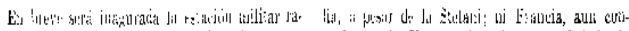

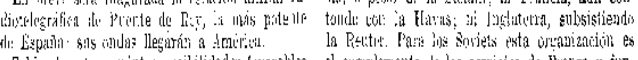

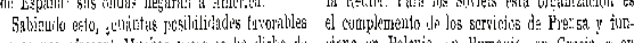

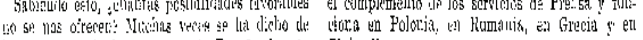

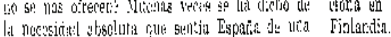

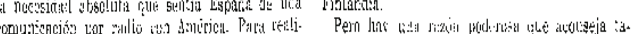

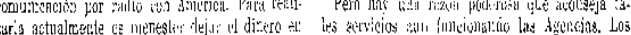

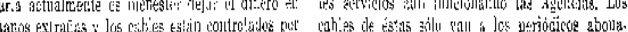

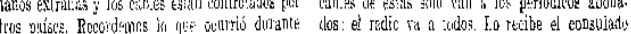

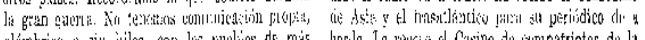

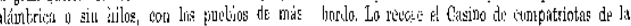

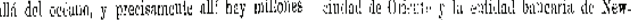

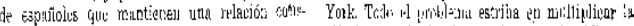

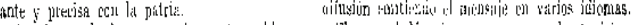

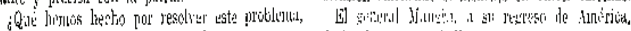

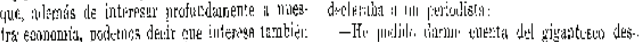

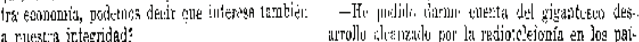

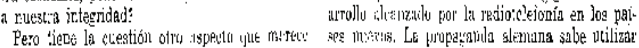

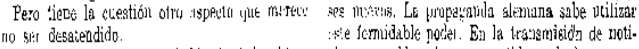

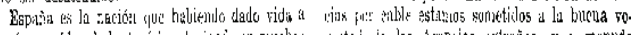

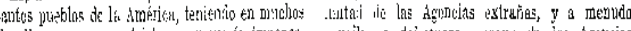

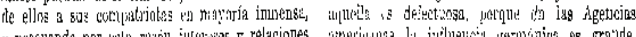

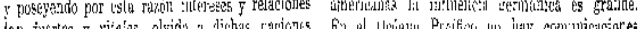

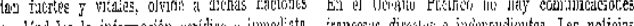

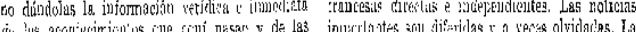
2.

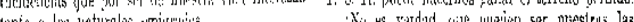

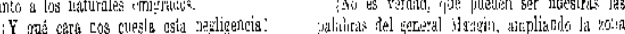

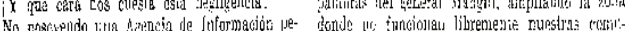

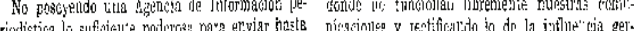
and

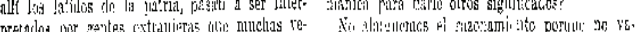

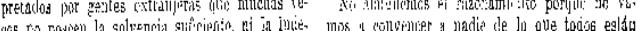

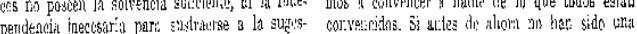

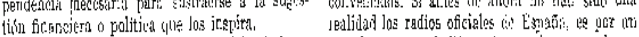

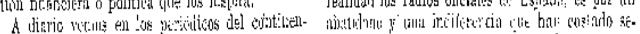

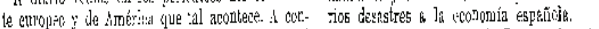

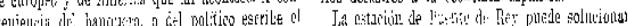

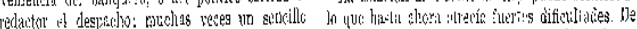

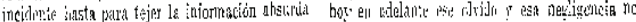

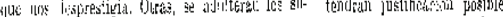

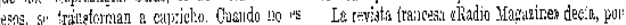

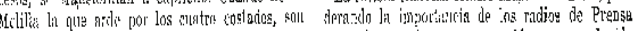

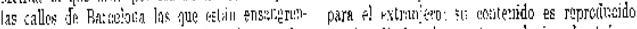

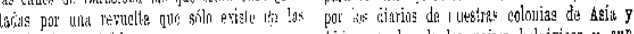

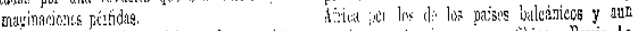

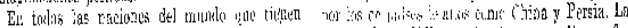

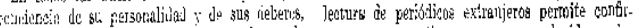

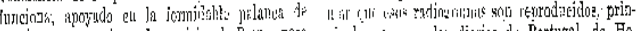

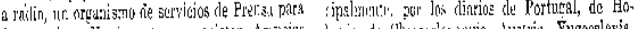

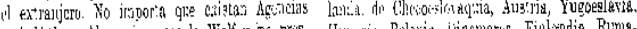

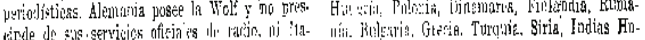

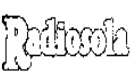


Quando analisamos as capas da revista

Radio Barcelona, a partir de setembro de

1924, podemos perceber as mudanças de

linha editorial e gráfica por que passou,

incorporando os novos tempos que sacodem

toda a programação das rádios. A revista Radio

Barcelona inova com divulgação mais completa

em vários assuntos, agora mais ampla e com

melhor exposição publicitária, mais ousadia

nas fotos e nas matérias. É a coqueluche da

Espanha. A iconografia é realmente inovadora,

pois até então se privilegiava o texto,

principalmente pelas limitações técnicas da

época. A inovação mais sentida, do ponto de

vista gráfico, foi a mudança do formato, que

passa de 14,7 cm X 21,0 cm (Radiosola) para

21,0 cm X 29,7 cm (Radio Barcelona). Outra

grande mudança, ocorre na linha editorial

pois a revista aumenta sensivelmente 0 espaço

político, inova com análises e cria novos

conceitos para a mídia impressa da época,

basicamente jornais. Tais mudanças também

estão no cerne da programação e na história

da EAJ-1 Radio Barcelona.

Em outro momento, já em 1936, percebemos

que, de acordo com os acontecimentos da

Guerra Civil e as iniciativas dos rebeldes

franquistas, as capas e matérias vão cedendo

lugar às iniciativas políticas. De capas, anteriores ao início da guerra, com as mais belas e famosas atrizes principalmente norteamericanas, a revista passa a destacar, num primeiro momento, os locais de Barcelona, representando a autonomia e a identidade da cidade catalã, e, num segundo momento, a partir do número 609, de 18 de abril de 1936, destacase a grandeza e força bélica da Catalunya. A partir deste momento a revista é incorporada pela Generalitat. ${ }^{2}$

Figura 8 - Reprodução da capa, da revista Radio Barcelona (Espanha), n. 632, de 21 de novembro de 1936

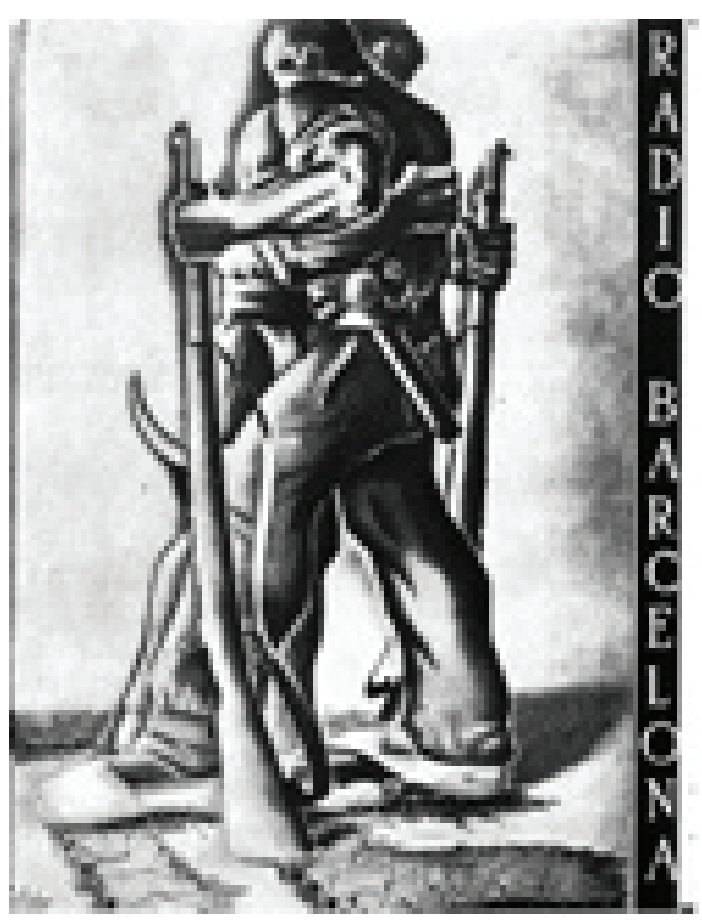

Fonte: Arxiu Històric de La Ciutat de Barcelona. 
Figura 9 - Reprodução da capa, da revista Radio Barcelona (Espanha), n. 624, de 26 de setembro de 1936

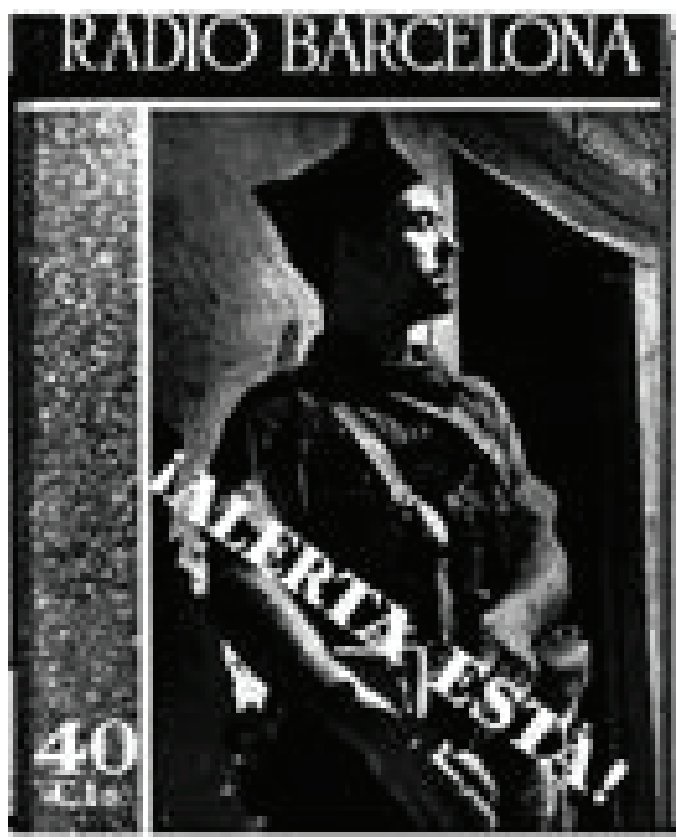

Fonte: Arxiu Històric de La Ciutat de Barcelona.

Um fator que nos chama a atenção sobre as revistas é a forma com que caem no agrado popular e adquirem no pré-guerra e durante a guerra civil, o status de veículo do governo catalão. Aliás, não apenas a revista (que durante 0 conflito é escrita em catalão), mas também a EAJ-1 e a Ràdio Asociació de Catalunya, que não tratamos neste texto. Estes veículos tiveram realmente papel fundamental para a luta republicana na Espanha.

Quando começamos nossa pesquisa uma questão que nos chamava a atenção era onde estavam os números de 1 a 12 da revista Radio Barcelona. Na busca de dados, percebemos que o primeiro número publicado é o 13, ano II, em setembro
Figura 10 - Reprodução da capa da Revista Radio Barcelona (Espanha) n 631 de 14 de novembro de 1936.

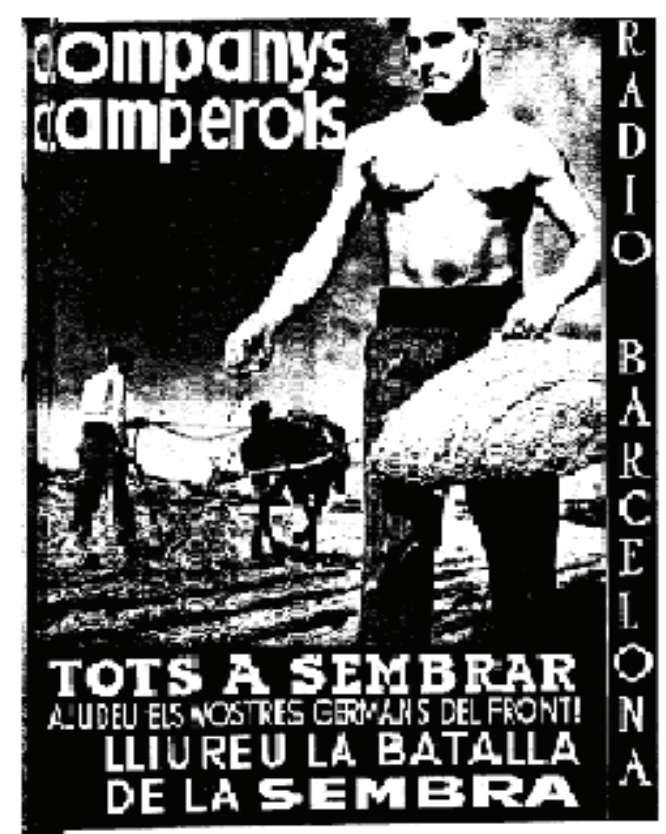

Fonte: Arxiu Històric de La Ciutat de Barcelona.

de 1924. Outra questão oriunda desta primeira então nos surge, ou seja, constatamos que 0 número 13 da revista Radio Barcelona não tem a data de publicação. Procurando resposta, conseguimos a data, um pouco mais tarde, consultando documentos do Arxiu Històric de la ciutat, da biblioteca da Catalunya. A data, segundo documentos do arquivo é setembro de 1924. Entendemos então que se tratava de edição que dava continuidade às edições da Radiosola, alterando apenas o título da revista para a mesma razão social da rádio. É por isso, para não haver confusão, que quando tratamos da rádio e da revista, citamos a rádio com o prefixo EAJ-1. 
Figura 11 - Reprodução da capa da revista Radio Barcelona (Espanha), n. 13, de setembro de 1924 (primeiro número da revista que continua a edição da Radiosola. Capa: Viola Dana, la conocida artista de la "Metro Pictures", gran apasionada de la radio).

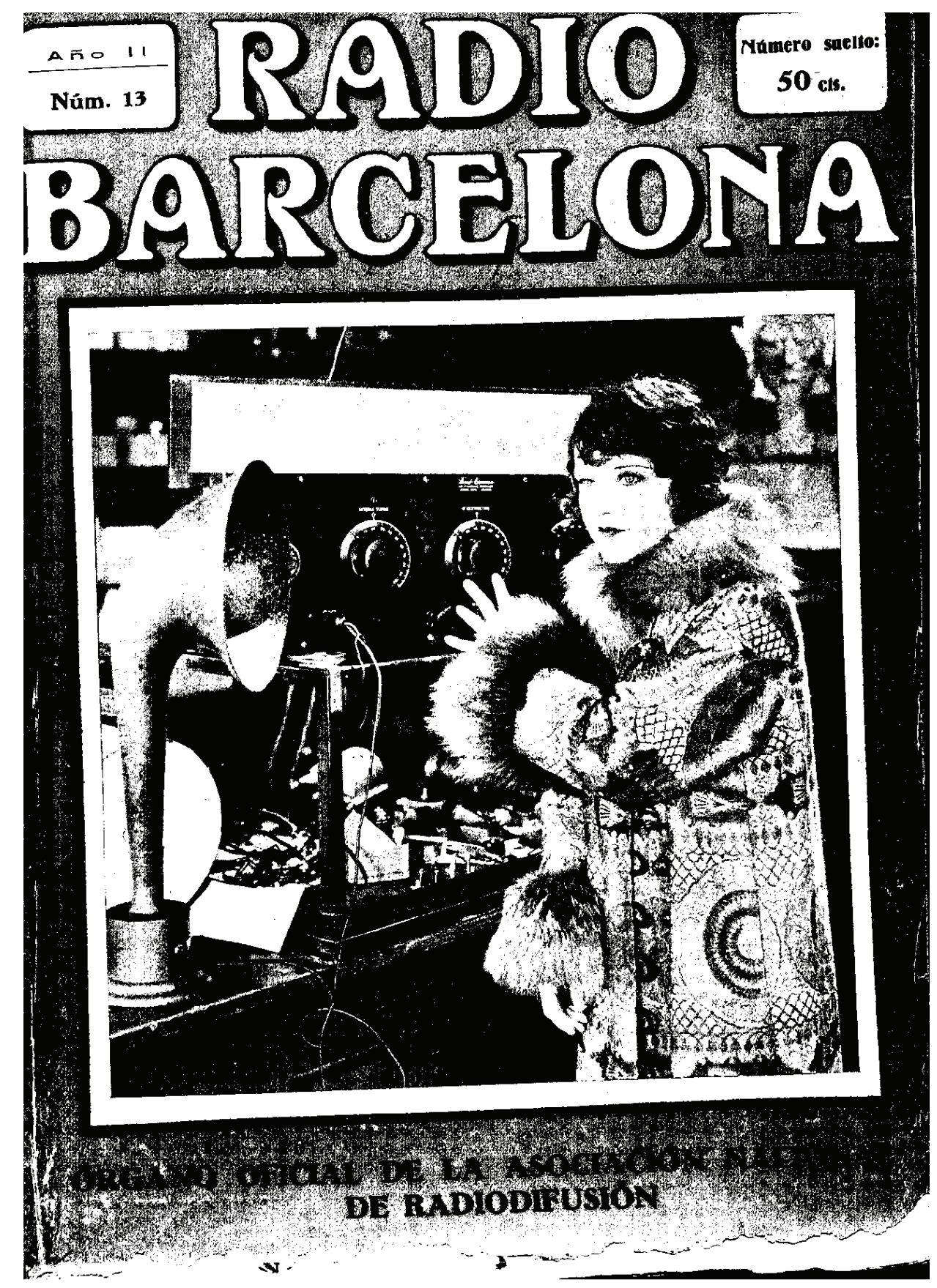

Fonte: Arxiu Històric de La Ciutat de Barcelona. 
Figura 12 - Reprodução da página 1 da revista Radio Barcelona (Espanha), n. 13, de setembro de 1924 (primeiro número da revista que continua a edição da Radiosola. "Cuatro Palabras" editorial apresentando a revista como integrande impresso da Rádio Barcelona.

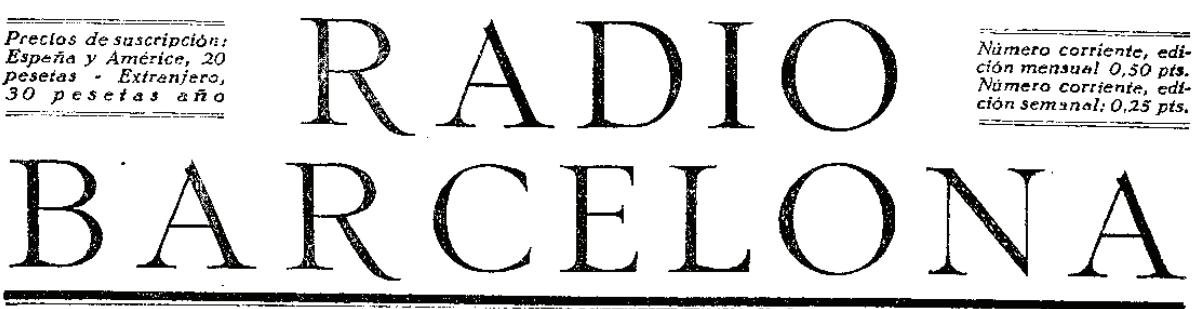
ÓRGANO OFICIAL DE LA ASOCIACINN NACIONAL DE KADIOTELEFONIA Redacción y Administración: Caspe, 12, I $^{\circ}$ - Teléf. $4427 \mathrm{~A}$.

\section{SUMARIO}

En la cubierta: Viola Dana, la conocida artista de la «Metro Picture», gran apasionada de la radio.Cuatro palabras. - La organización de las «Ëmisiones Radio-B̈arcelona». - Inauguración de las «Emisiones Radio-Barcelona». - Inauguración de Radio. España. - La T. S. H. y el problema del campo, Joaquin 'Artarás. - Procedimientos para evitar la interferencia, Sexion O'connot. - Por el nabla castellana. - Un receptor para on das de 40 a 160 metros, J. M. Gómez. - Para convertir los aparatos corrientes en anfiradiactivos por medio de lámpara de «complage», Ernesto Ferrer. - El Ârte Musical y la Radiotelefonía, Salvodor Raurich. - Hacia la edad de oro, Arturo S. Burroughs. - Aparato a un so'o tubo y de cristal para la recepción de transmisiones en alta voz, N. N. Bernstein. - Ecos de la radiodifusion. - La RadioBarcelona en sas conferencias de carácter agro-pecuario transmitidas por rááodifusion (conferencio inaugural oido del profesor D. Salvador Castelló. - Programa de las emisiones

\section{CUATRO PALABRAS}

A Asociación Nacional de Radiodifusión al $L$ iniciar la consirucción de la emisora de Broadcasting, creyó indispensable puseer un órgano en la prensa radioeléctrica pará realizar la difusión de sus ideas, proyectos y programas. Facilitaron la ejecración de nuestros propósitos, la feliz iniciativa de los socios señores Solá y Guillen-García propietarios de la revista $\{$ Radiosolar que se publicaba desde hace meses, los cuales desde al primer momento y para no entorpecer nuestros proyectos, decïdieron suspender dicha publicación para dejar ancho campo de accíón a la A. N. de R. $y$ así desarrollar la nueva publicación RADIOBARCELONA, fuerte y pujante sin la posible sombra de otra similar.

Al aparecer en el estadio de la prensa, no pretendemos establecer competencias ni rivalidades con las ya establecidas, nada de eso, nuestra revista que serí el brgano oficial de la Asociación Nacional de Radiodifusión tendrá por primordial objeto el exponer a marcha de nuestra ertidad, facilitat una amplia, infor. mación sobre los nuevos inventos o estaciones radioeléctricas ast como los más modernos montajes sin descuidar la crítica de las emisiones que es indispensab e para acrecentar y divalgar a cuitura musica entre sos radioyentes. Deseamos la colaboración de todos desde el hombre de ciencía que encerrado en su laboratorio descubre nuevas eyes, hasta e sencillo operatio que en el taller modifica una pieza, pasando por el aficionado, este factor ind spensab'e y de tanta valia en radio que ejecutando constantemente nuevos ensayos descubte mantajes $y$ disposiciones que zevolucionan la radio eiectricidad.

De todos necesita nuestra Revista y por ello nuestras co umnas están abiertas a todos los hombres de fecunda imaginación o pacientes investigadores.También necesitamos de $t$, caro lector, para que con tus consejos y observaciones esta Revista sea fiel refiejo de todo y resultante de nuestros deseos.

$Y$ para terminar, solo nos resta enviar un Caiuroso y fraternal saludo a nuestros co'cgas de la prensa ast diaría como especta'izada, especiatmente a aquellos, ya numerosos que se editan allende de los mares en nuestro Idioma.

Fonte: Arxiu Històric de La Ciutat de Barcelona. 
0 sucesso da revista Radio Barcelona, vinculada à EAJ-1 Radio Barcelona, foi tão grande, que no mês de dezembro de 1924, passou a ter periodicidade semanal. Foram publicados quatro números, o número 16, em 06 de dezembro de 1924; o número 17, em 15 de dezembro de 1924; 0 número 18, em 20 de dezembro de 1924 e o número 19, em 27 de dezembro de 1924. Podemos imaginar, pela precariedade técnica da época, o trabalho que deu fazer tantas revistas em tão curto período.
0 mesmo ocorre no mês de janeiro de 1925.0 primeiro número sai em 3 de janeiro de 1925; 0 segundo número em 10 de janeiro de 1925; 17 de janeiro de 1925; 24 de janeiro de 1925 e 31 de janeiro de 1925.

Abaixo descrevemos as capas da revista Radiosola, a transformação para Radio Barcelona, e demais capas até fevereiro de 1925.

Quadro 1 - Capas da revista Radiosola:

\begin{tabular}{|c|c|c|c|}
\hline Año & Número & Data & Capa \\
\hline I & 1 & septiembre 1923 & Deseño do palacio de Montjuic \\
\hline I & 2 & octubre 1923 & Deseño do palacio de Montjuic \\
\hline I & 3 & noviembre 1923 & $\begin{array}{l}\text { Foto de Percy Marmont, Geriradis Hort e Ralf E. Bushman - } \\
\text { deleitando-se en un aparato radiotelefónico durante un descanso }\end{array}$ \\
\hline$\|$ & 5 & enero-frebreiro 1924 & $\begin{array}{l}\text { Foto: La radiodifusión en el campo - una família escuchando la } \\
\text { ópera }\end{array}$ \\
\hline$\|$ & 7 & marzo-abril 1924 & foto: como se transmite un concierto \\
\hline$\|$ & $9-10$ & mayo-junio 1924 & $\begin{array}{l}\text { Wanda Marley la bella actriz de la Paramount, una de las más } \\
\text { aficionadas a la radio }\end{array}$ \\
\hline$\|$ & $11-12$ & julio-agosto 1924 & $\begin{array}{l}\text { emisión emisora de la revista } \\
\text { "T.S.H. Moderne" de Paris }\end{array}$ \\
\hline
\end{tabular}


Quadro 2 - Capas da revista Radio Barcelona

\begin{tabular}{|c|c|c|c|}
\hline Año & Número & Data & Capa \\
\hline II & 13 & septiembre 1924 & $\begin{array}{l}\text { Viola Dana, la conocida artista de la "Metro Pictures", } \\
\text { gran apasionada de la radio }\end{array}$ \\
\hline II & 14 & 23 de noviembre de 1924 & $\begin{array}{l}\text { Las autoridades e invitados en el acto de inauguración de } \\
\text { EAJ-1 Radio Barcelona, instala en el Hotel Colón }\end{array}$ \\
\hline II & 15 & 20 de noviembre de 1924 & $\begin{array}{l}\text { Nuestras instalaciones. Sala de conciertos, en el Hotel } \\
\text { Colón, para las emisiones de Radio Barcelona }\end{array}$ \\
\hline II & 16 & 6 de diciembre de 1924 & $\begin{array}{l}\text { El president de Radio Club Anglo-Franco-Americano, } \\
\text { contratando un aparato de } 500 \text { watt }\end{array}$ \\
\hline II & 17 & 15 de diziembre de 1924 & $\begin{array}{l}\text { Corinne Griffit, estrella de la National Pictures, escuchando } \\
\text { un concierto por radio }\end{array}$ \\
\hline II & 18 & 20 de diziembre de 1924 & Pequeño cazador de ondas \\
\hline II & 19 & 27 de diziembre de 1924 & $\begin{array}{l}\text { Salón transmisor BELL, de los radioconciertos, con el } \\
\text { micrófono cerca del concertante }\end{array}$ \\
\hline III & 20 & 3 de enero de 1925 & $\begin{array}{l}\text { Aparato de } 3 \text { lámparas - detectora y dos bajas - } \\
\text { montado a base del último esquema americano conocido } \\
\text { vulgarmente el tipo " } 7000 \text { millas" }\end{array}$ \\
\hline II & 21 & 10 de enero de 1925 & $\begin{array}{l}\text { estación transmisora L.L. adquirida para radiodifusión de } \\
\text { Sevilla }\end{array}$ \\
\hline ॥ & 22 & 17 de enero de 1925 & $\begin{array}{l}\text { El ingeniero D. Pablo Llorens, nuevo Presidente de la } \\
\text { Asociación Nacional de Radiodifusión }\end{array}$ \\
\hline II & 23 & 24 de enero de 1925 & $\begin{array}{l}\text { cuadro de control de líneas microfónicas que unen los } \\
\text { teatros con la emisora Radio Barcelona }\end{array}$ \\
\hline ॥ & 24 & 31 de enero de 1925 & $\begin{array}{l}\text { Altav0z Gaumont instalado en Palace Hotel de Madrid, } \\
\text { durante la reciente exposición de T.S.H. }\end{array}$ \\
\hline$\|$ & 25 & 7 de febrero de 1925 & La emisora E.A.J.1 situada en el Gran Hotel Colón \\
\hline ॥ & 26 & 14 de febrero de 1925 & $\begin{array}{l}\text { La gentil típli ligera Julita Cuyás, artista de la Radio } \\
\text { Barcelona }\end{array}$ \\
\hline II & 27 & 21 de febrero de 1925 & $\begin{array}{l}\text { Sala de conciertos de la Casa Werner, que retrasmite } \\
\text { "Rádio Barcelona" }\end{array}$ \\
\hline ॥ & 28 & 28 de febrero de 1925 & $\begin{array}{l}\text { Vista exterior de la estación receptora Marconi, del } \\
\text { Cuadro del Campo de la Sota (Barcelona), que establece la } \\
\text { comunicación de Alemania, Austria e Italia, con Espanha. }\end{array}$ \\
\hline
\end{tabular}




\section{A EAJ-1 Radio Barcelona e a Guerra Civil Espanhola (1936-1939)}

Trazemos aqui de forma resumida alguns fatos da guerra, para entendermos o papel que os veículos estudados exerceram no conflito, que tem tem início em 17 de julho de 1936, e termina em $1^{\circ}$ de abril de 1939, "dia mundial da mentira". Há fatos curiosos, do ponto de vista histórico, que antecedem e criam as condições políticas e históricas para a eclosão desta guerra.

Após a ascensão ao poder de Miguel Primo de Rivera y Orbaneja (1923-1930), a Espanha passa por um curto período, que pode ser denominado "período de transição", tendo como Presidentes o General Dámaso Berenguer y Fusté (1930) e Juan Bautista Aznar-Cabañas (1931). Após este período havia todas as condições para a ascensão da Segunda República (1931-1935), que também extremamente radicais, criam as condições para a sublevação dos generais golpistas liderados por Francisco Franco. Podemos afirmar que 0 rádio esteve presente em todos estes momentos acompanhando os fatos e a EAJ-1 Radio Barcelona, acompanhou passo a passo a evolução política e os conflitos, ao lado da República, até a entrada triunfal de Franco pelas ruas de Barcelona, em 1939.
0 recorte histórico onde se encontra o nascimento do rádio e da EAJ-1 coincide com a ascenção da ditadura de Rivera, período da história espanhola, que compreende desde 0 Golpe de Estado do capitão-general Miguel Primo de Rivera, em 13 de setembro de 1923, até 28 de janeiro de 1930, quando da sua substituição pela chamada Dictablanda, ${ }^{3}$ do general Dámaso Berenguer, sucedido por Juan Bautista Aznar-Cabañas.

Enquanto a cena política se construía na Espanha, por outro lado também a radiofusão em 1923 ensaiava os primeiros passos, juntamente com os EUA, Alemanha, França, Itália, Russia, também na América Latina, principalmente no Brasil, Argentina, Uruguai, Chile e México. ${ }^{4}$ Na Espanha porém, os governos de Dámaso Berenguer e de Juan Bautista Aznar-Cabañas, não fizeram outra coisa a não ser aumentar a decadência e 0 descontentamento popular. Depois do fracasso da Dictablanda, Alfonso XIII tentou devolver o frágil regime monárquico à instância parlamentar, convocando eleições municipais para 12 de abril de 1931. Constatando a falta de apoio popular nas cidades, o Rei Afonso XIII, decidiu exilar-se na França em 14 de abril de 1931, afastando, contra sua vontade

A dictablanda é um período (1930-1931), que compreende os anos entre o final da ditadura de Primo de Rivera (1923-1930) e a chegada da Segunda República ao poder (1931-1935). Foi na verdade um governo de transição, quando o general Dámaso Berenguer substituiu o general Primo de Rivera. Berenguer governou por decretos e teve como função principal dos mandadários da Espanha apaziguar os ânimos para que a transição para a Segunda República não ocorresse de forma revolucionária. Tratou de acalmar estrategicamente os ânimos na Espanha após a queda da Bolsa de 1929 e as revoltas sociais. A dictablanda exerceu 0 papel de carrasco de Primo de Rivera e executou em um ano mais sentenças de morte por motivos políticos do que todos os anos da ditadura de Rivera. 
mas por pressão popular, os Bourbons do poder. Vamos fazer abaixo uma evolução cronológica da guerra civil, para que se compreenda melhor os fatos naquele momento histórico. Barcelona e Madrid foram as últimas regiões a cair sob o poderio militar de Franco, apoiado pela Itália, Alemanha e Portugal.

0 marco inicial da Guera Civil está na sublevação de Melilla, em 17 de julho de 1936, momento em que há o primeiro pronunciamento militar, com caráter de conflito bélico, a guerra. 0s rebeldes militares se encaminham para o Sul da Espanha e por lá montam a seu quartel general. A França em $1^{0}$ de agosto de 1936 propõe um pacto de nãointervenção na Espanha e, baseada neste acordo, costurado pela potências para não criar um clima hostil à Alemanha, Itália e seus aliados, fecha os olhos para o início de uma das mais terríveis barbáries do século XX. Em 14 de agosto, ocorre o massacre de Badajoz contra civis e militares defensores da Segunda República e em 27 de agosto, ocorre 0 primeiro bombardeio de Madrid.

Os militares franquistas se sentiam muito fortes, pois já tinham 0 apoio dos alemães e italianos, e nessa linha é que em $1^{\circ}$ de outubro, Francisco Franco passa a ser chefe de governo e "generalíssimo" dos exércitos. Em 4 de novembro suas tropas avançam na direção de Madrid e ocupam várias cidades e em 18 de novembro, a Alemanha e a Itália reconhecem o governo dos rebeldes, já denominados "nacionalistas", por um grupo de propaganda do Reich, que desembarca na Espanha com o que há de mais moderno em tecnologia de comunicação da época, da empresa Telefunken, construindo uma grande cadeia de rádio, segundo Fernández Sande (2006), para anunciar os discursos de Franco e suas vitórias contra os agora "traidores da pátria", discurso organizado e alardeado por Joseph Goebbels, Ministro da Propaganda do Terceiro Reich. Em 22 de dezembro, os fascistas italianos, também denominados de "camisas negras", descem em Cádiz. Da Alemanha chegam 15 mil soldados, principalmente da aviação, da Luftwaffe, e da Itália 70 mil soldados. Enquanto os alemães bombardeiam via aérea as regiões republicanas, os italianos por sua vez são responsáveis pelo fechamento dos portos, evitando assim 0 abastecimento da população, que já começava a dar apoio aos rebeldes, após massiva propaganda radiofônica e também pelas agruras da guerra. Entre fevereiro, março, abril e maio de 1937, aviões alemães bombardeiam Durango, Ochandiano e Guernica, esta última eternizada no painel pintado por Pablo Picasso, e fazem grande ofensiva ao norte da Espanha, encerrada em outubro. Em $1^{0}$ de outubro, o governo republicano se transfere para Valência. Em dezembro, ocorre bombardeio golpista em Barcelona e em 2 de março de 1938, é abolida a liberdade de expressão e de reunião, na área dominada pelos golpistas. Em setembro de 1938, novamente Barcelona é pesadamente bombardeada, tendo o porto, principal ponto de chegada e escoamento de todo tipo de produto de Barcelona, sido praticamente destruído,. Neste 
momento em Barcelona o caos radiofônico está implantado e a situação é muito próxima do que acontecia em Madrid. A guerra está no seu auge e não seria anormal que isto viesse a ocorrer. Várias emissoras de ondas curtas de partidos e sindicados estão operando simultaneamente com a Radio Barcelona e a Ràdio Asociació de Catalunya, que neste momento, segundo Balsebre (2001), coordenam-se entre si para suas emissões, inclusive de propaganda de guerra, dirigidas a partir da Generalitat, pela Dirección General de Radiodifusión de Josep Fontbernat, com a participação também do Comisario de Propaganda, o jornalista Jaume Miravitlles. 0 exército de terra também opera uma rádio de onda curta conhecida como La Voz de España e é controlada por membros do Partido Comunista.

Há um momento na Espanha de 1937, portanto na segunda etapa da guerra, que ambos os lados, republicanos e militares rebeldes, querem centralizar com uma voz única, as transmissões radiofônicas, para que não haja descontrole de informações e ações. Em ambos os lados há acompanhamento e censura muito rígida com relação à audição de transmissão de emissoras inimigas. É neste ambiente que proliferam as emissoras clandestinas e os ouvintes clandestinos, que ouviam bem baixo e em locais ermos, para não serem tratados como espiões, por ambos os lados.

Em dezembro de 1938 a frente republicana em Barcelona é praticamente varrida do mapa, com o avanço das tropas golpistas em janeiro de 1939.
Em 21 de fevereiro, Franco desfila comemorando a vitória pelas Ramblas de Barcelona, com uma população aos farrapos e sem forças para continuar a guerra. Em 28 de março entram em Madrid e em $1^{0}$ de abril, conseguem seus fins militares, com o fim da guerra fratricida.

\section{Referências}

\section{ARGÜELLES-MERES, Luis Arias. Azaña o el}

sueño de la razón. Madrid: Editorial Nerea 1990.

\section{BALSEBRE, Armand. Historia de La radio en}

España. Madrid: Cátedra Signo e imagen, 2001. v. I.

BALSEBRE, Armand. El lenguaje radiofónico.

5. ed. Madrid: Cátedra, 2007. BUSTILLO, Josefina

Cuesta. Sindicalismo católico agrário -

Espanha 1917-1919. Madrid: Narcea, 1978.

FERNÁNDEZ SANDE, Manuel. Orígenes de La radio em España. La competência entre Unión Radio y Radio Ibérica (1925-1927). Madrid:

Editorial Fragua, 2006. v. II.

FUNARI, Pedro Paulo A. 0s perigos da tecnologia moderna para a preservação dos documentos. Campinas-SP, [1999]. Disponível em < http://www. unicamp.br/siarq/publicacoes/perigos_tecnologia_ documentos.pdf > . Acesso em: 10 out. 2010.

GARRIGA, Teodor. La meva vida i Ràdio

Associació de Catalunya. Barcelona: Proa, 1998.

PAZ, Abel. Guerre d'Espagne. Paris: Éditions Hazan, 1997. 


\section{EAJ-1 Radio Barcelona and the magazines Radiosola and Radio Barcelona in the years of 1920 and 1930: times of political turmoil}

\section{Abstract:}

This article originates from the post doctoral research, completed in 2009, with support from FAPESP, in PUCSP and the Universitat Autònoma de Barcelona-UAB. Our aim is to analyze the magazines Radiosola and Radio Barcelona in the consolidation of EAJ-1 Radio Barcelona, Spain's first official radio station, in 1924. The theoretical discussion is based on publications in the fields of media and media history. We work with observations, document analysis, audiovisual material, researches in newspapers and journals, and interviews with professionals of Radio Barcelona and cited journals. The oral history has proved to have been extremely useful for the bias of diachronic research, given the oral fertility of radio media. We conclude that magazines are of vital importance and a mainstay of radio by the end of the Civil War (1939), times of great political turmoil, and also important for the success of the cinema in Spain, with illustrated covers by the most beautiful actresses of that time.

\section{Keywords:}

Media History. Radio and Politics. Barcelona Radio. Radiosola magazine. Radio Barcelona magazine.

\section{EAJ-1 Radio Barcelona y las revistas Radiosola y Radio} Barcelona en los años 1920 y 1930: tiempos de turbulencia política

\section{Resumen:}

Este artículo tiene origen en estudio de posdoctorando, concluida el 2009, con apoyo de la FAPESP, en la PUCSP y en la Universitat Autònoma de Barcelona-UAB. Nuestro objetivo es analizar las revistas Radiosola y Radio Barcelona en la consolidación de la EAJ-1 Radio Barcelona, la primera estación oficial de España, en 1924. La reflexión teórica tiene como base publicaciones en los campos mediático e historia de los medios. Trabajamos con la observación, análisis documental, material audiovisual, estudio en periódicos y revistas españolas y entrevistas con profesionales de la Radio Barcelona y de las revistas citadas. La historia oral nos fue extremamente útil para el sesgo diacrónico del estudio, dada la fertilidad oral del medio radio. Concluimos que las revistas son de vital importancia y un puntal de la radio hasta el final de la Guerra Civil (1939), tiempos de gran turbulencia política, y también importantes para el éxito del cine en España, con capas ilustradas por las más hermosas actrices de la época.

\section{Palabras clave:}

Historia de los Medios. Radio y Política. Radio

Barcelona. Revista Radiosola. Revista Radio Barcelona. 


\section{Expediente}

A revista E-Compós é a publicação científica em formato eletrônico da Associação Nacional dos Programas de Pós-Graduação em Comunicação (Compós). Lançada em 2004, tem como principal finalidade difundir a produção acadêmica de pesquisadores da área de Comunicação, inseridos em instituições do Brasil e do exterior.

\section{E-COMPÓS I www.e-compos.org.br I E-ISSN 1808-2599}

Revista da Associação Nacional dos Programas de Pós-Graduação em Comunicação.

Brasília, v.14, n.1, jan/abr. 2011

A identificação das edições, a partir de 2008

passa a ser volume anual com três números.

\section{CONSELHO EDITORIAL}

Afonso Albuquerque, Universidade Federal Fluminense, Brasil Alberto Carlos Augusto Klein, Universidade Estadual de Londrina, Brasil Alex Fernando Teixeira Primo, Universidade Federal do Rio Grande do Sul, Brasil Ana Carolina Damboriarena Escosteguy, Pontifícia Universidade Católica do Rio Grande do Sul, Brasil

Ana Gruszynski, Universidade Federal do Rio Grande do Sul, Brasil Ana Silvia Lopes Davi Médola, Universidade Estadual Paulista, Brasil André Luiz Martins Lemos, Universidade Federal da Bahia, Brasil Ângela Freire Prysthon, Universidade Federal de Pernambuco, Brasil Angela Cristina Salgueiro Marques, Faculdade Cásper Líbero (São Paulo), Brasil Antônio Fausto Neto, Universidade do Vale do Rio dos Sinos, Brasil Antonio Carlos Hohlfeldt, Pontifícia Universidade Católica do Rio Grande do Sul, Brasil Antonio Roberto Chiachiri Filho, Faculdade Cásper Líbero, Brasil Arlindo Ribeiro Machado, Universidade de São Paulo, Brasil Arthur Autran Franco de Sá Neto, Universidade Federal de São Carlos, Brasil Benjamim Picado, Universidade Federal Fluminense, Brasil César Geraldo Guimarães, Universidade Federal de Minas Gerais, Brasil Cristiane Freitas Gutfreind, Pontifícia Universidade Católica do Rio Grande do Sul, Brasil Denilson Lopes, Universidade Federal do Rio de Janeiro, Brasil Denize Correa Araujo, Universidade Tuiuti do Paraná, Brasil Edilson Cazeloto, Universidade Paulista, Brasil Eduardo Peñuela Cañizal, Universidade Paulista, Brasil Eduardo Vicente, Universidade de São Paulo, Brasi Eneus Trindade, Universidade de São Paulo, Brasil Erick Felinto de Oliveira, Universidade do Estado do Rio de Janeiro, Brasil Florence Dravet, Universidade Católica de Brasília, Brasil Francisco Eduardo Menezes Martins, Universidade Tuiuti do Paraná, Brasil Gelson Santana, Universidade Anhembi/Morumbi, Brasil Gilson Vieira Monteiro, Universidade Federal do Amazonas, Brasil Gislene da Silva, Universidade Federal de Santa Catarina, Brasi Guillermo Orozco Gómez, Universidad de Guadalajara Gustavo Daudt Fischer, Universidade do Vale do Rio dos Sinos, Brasil Hector Ospina, Universidad de Manizales, Colômbia Herom Vargas, Universidade Municipal de São Caetano do Sul, Brasil leda Tucherman, Universidade Federal do Rio de Janeiro, Brasil Inês Vitorino, Universidade Federal do Ceará, Brasil Janice Caiafa, Universidade Federal do Rio de Janeiro, Brasil Jay David Bolter, Georgia Institute of Technology Jeder Silveira Janotti Junior, Universidade Federal de Pernambuco, Brasil João Freire Filho, Universidade Federal do Rio de Janeiro, Brasil
John DH Downing, University of Texas at Austin, Estados Unidos José Afonso da Silva Junior, Universidade Federal de Pernambuco, Brasil José Carlos Rodrigues, Pontifícia Universidade Católica do Rio de Janeiro, Brasil José Luiz Aidar Prado, Pontifícia Universidade Católica de São Paulo, Brasil José Luiz Warren Jardim Gomes Braga, Universidade do Vale do Rio dos Sinos, Brasi Juremir Machado da Silva, Pontifícia Universidade Católica do Rio Grande do Sul, Brasil Laan Mendes Barros, Universidade Metodista de São Paulo, Brasil Lance Strate, Fordham University, USA, Estados Unidos Lorraine Leu, University of Bristol, Grã-Bretanha Lucia Leão, Pontifícia Universidade Católica de São Paulo, Brasil Luciana Panke, Universidade Federal do Paraná, Brasil Luiz Claudio Martino, Universidade de Brasília, Brasil Malena Segura Contrera, Universidade Paulista, Brasil Márcio de Vasconcellos Serelle, Pontifícia Universidade Católica de Minas Gerais, Brasi Maria Aparecida Baccega, Universidade de São Paulo e Escola Superior de Propaganda e Marketing, Brasil

Maria das Graças Pinto Coelho, Universidade Federal do Rio Grande do Norte, Brasil Maria Immacolata Vassallo de Lopes, Universidade de São Paulo, Brasil Maria Luiza Martins de Mendonça, Universidade Federal de Goiás, Brasil Mauro de Souza Ventura, Universidade Estadual Paulista, Brasil Mauro Pereira Porto, Tulane University, Estados Unidos Nilda Aparecida Jacks, Universidade Federal do Rio Grande do Sul, Brasil Paulo Roberto Gibaldi Vaz, Universidade Federal do Rio de Janeiro, Brasil Potiguara Mendes Silveira Jr, Universidade Federal de Juiz de Fora, Brasil Renato Cordeiro Gomes, Pontifícia Universidade Católica do Rio de Janeiro, Brasi Robert K Logan, University of Toronto, Canadá

Ronaldo George Helal, Universidade do Estado do Rio de Janeiro, Brasil Rosana de Lima Soares, Universidade de São Paulo, Brasil Rose Melo Rocha, Escola Superior de Propaganda e Marketing, Brasil Rossana Reguillo, Instituto de Estudos Superiores do Ocidente, Mexico Rousiley Celi Moreira Maia, Universidade Federal de Minas Gerais, Brasil Sebastião Carlos de Morais Squirra, Universidade Metodista de São Paulo, Brasil Sebastião Guilherme Albano da Costa, Universidade Federal do Rio Grande do Norte, Brasil

Simone Maria Andrade Pereira de Sá, Universidade Federal Fluminense, Brasil Tiago Quiroga Fausto Neto, Universidade de Brasília, Brasil Suzete Venturelli, Universidade de Brasilia, Brasil

Valério Cruz Brittos, Universidade do Vale do Rio dos Sinos, Brasil Valerio Fuenzalida Fernández, Puc-Chile, Chile Veneza Mayora Ronsini, Universidade Federal de Santa Maria, Brasil Vera Regina Veiga França, Universidade Federal de Minas Gerais, Brasil

\section{COMISSÃO EDITORIAL}

Adriana Braga I Pontifícia Universidade Católica do Rio de Janeiro, Brasil Felipe Costa Trotta I Universidade Federal de Pernambuco, Brasi CONSULTORES AD HOC

Édison Gastaldo I Universidade Federal Rural do Rio de Janeiro, Brasil Gisela Grangeiro da Silva Castro, Escola Superior de Propaganda e Marketing, Brasil Helio Kuramoto, Instituto Brasileiro de Informação em Ciência e Tecnologia, Brasil Juliano Maurício de Carvalho, Universidade Estadual Paulista, Brasil Maria Helena Weber, Universidade Federal do Rio Grande do Sul, Brasi Paulo Carneiro da Cunha Filho, Universidade Federal de Pernambuco, Brasil Vera Regina Veiga França, Universidade Federal de Minas Gerais, Brasil EDIÇÃO DE TEXTO E RESUMOS I Susane Barros SECRETÁRIA EXECUTIVA I Juliana Depiné EDITORAÇ̃̃o ELETRÔNICA I Roka Estúdio
COMPóS I www.compos.org.br

Associação Nacional dos Programas de Pós-Graduação em Comunicação

Presidente

Itania Maria Mota Gomes

Universidade Federal da Bahia, Brasil

itania@ufba.br

Vice-presidente

Julio Pinto

Pontifícia Universidade Católica de Minas Gerais, Brasil juliopinto@pucminas.br

Secretária-Geral

Ana Carolina Escosteguy

Pontifícia Universidade Católica do Rio Grande do Sul, Brasil carolad@pucrs.br 